well-known hospitals, old spas, and other places of great medical achievements.

Society is always demanding that the medical schools produce better doctors. If they have the aim of giving the student an education which enables him to fulfil his duties and responsibilities as a member of the profession and of the community, a good medical historian may contribute remarkably to the realization of this project. Certainly, how to reach this goal is still a subject of lively discussion in Germany, as it is in other countries. ${ }^{1}$

JOHANNES STEUDEL

${ }^{1}$ Cf. Education in the History of Medicine, ed. by John B. Blake, New York, 1968.

\title{
EPISTEME
}

The critical review of history of medical and biological sciences Episteme grants to the Members of the various National Societies of the History of Medicine and of the History of Science a discount of 10 per cent on the subscription price for 1970 ( $\$ 8.00$ instead of $\$ 9.00$ ), on condition that the reduced subscription price of $\$ 8.00$ will be sent directly to the Administration of the review (Episteme, Via Orti 5, 20122 Milano, Italy) through bank check or international postal order, indicating at the same time the Society of which one is Member. The same discount is reserved also to the Libraries of the scientific and university Institutes. In 1970 Episteme will be issued in four quarterly numbers.

\section{UNIVERSITY OF PARIS, DEPARTMENT OF THE HISTORY OF MEDICINE AND SURGERY}

A series of lectures devoted to 'Medicine and Surgery in the Seventeenth and Eighteenth Centuries' is taking place in the Faculté de Médecine, Paris, from 8 January to 21 May 1970, under the chairmanship of the Professor of History of Medicine and Surgery, Prof. Charles Coury. The course includes historical lectures on the circulation of the blood, physiology, pathological anatomy, cardiology, infectious diseases, histology, obstetrics and gynaecology, hospitals, etc.; and the work of contemporary physicians and scientists will be discussed. 